\title{
Processo Centrado no Usuário para Geração de Laudos Genéticos
}

\author{
Dyego C. S. de Morais ${ }^{1}$, Marcel P. Caraciolo ${ }^{2}$ \\ ${ }^{1}$ Centro de Informática - Universidade Federal de Pernambuco (UFPE) \\ Recife - PE - Brasil \\ ${ }^{2}$ Genomika Diagnósticos - Recife - PE - Brasil \\ moraisdcs@gmail.com, marcel@genomika.com.br
}

\begin{abstract}
The information complexity in clinical genetic reports brings to attention the need of insertion of users in your construction process. In this work, we detail an proposal for clinical genetic reports publishing in the digital format $(P D F)$ and its evolution to an interactive web interface. We use as case control genetic tests for healthcare, nutritional needs and response to physicial exercises. Those tests are performed by a clinical laboratory.

Resumo. A complexidade de informações em laudos de genética clínica traz a necessidade de inserção de usuários em seu processo de construção. Neste trabalho, descrevemos uma proposta de processo de produção de laudos de genética clínica em formato digital portável (PDF) e sua evolução para uma interface web interativa. Utilizamos como caso de estudo testes genéticos de bem-estar, saúde de necessidades nutricionais e resposta a exercícios físicos realizados em um laboratório clínico de testes genéticos.
\end{abstract}

\section{Introdução}

Com o avanço de novas tecnologias na última década, desde o primeiro genoma humano sequenciado, aplicações clínicas com o uso de dados genéticos têm surgido (Cariaso et al, 2012; Hamosh et al, 2005). Estas aplicações consistem no uso de bioinformática na busca de variantes específicas no DNA humano associadas com fenótipos ou doenças. Com posse destas informações genéticas, os especialistas como medicos ou biomédicos podem analisar as alterações, determinar se estas são ou não causadoras, e produzir a partir de suas conclusões o laudo técnico consolidado para ser entregue aos pacientes ou profissionais de saúde solicitantes. Todavia, devido ao grande volume de variantes genéticas, à sua complexidade, falta de profissionais com proficiência em genética e limitações dos pacientes e médicos na interpretação do laudo técnico é necessário que os laudos sejam gerados de forma individual, acessível e formatada em uma linguagem clara e de fácil compreensão.

Nesse contexto, o processo de Design Centrado no Usuário através do estudo de fatores humanos surge como uma alternativa que inclui o usuário no processo de construção de laudos interativos de exames genéticos. Este trabalho tem como objetivo apresentar o processo que está sendo executado para gerar laudos de testes genéticos e apresentá-los em PDF e em uma interface web com arquitetura de informações coerente e que facilite o entendimento aos médicos e pacientes. 
O processo está sendo aplicado ao exame genético de marcadores relacionados à metabolismo, dieta, exercícios, controle de peso, necessidades nutricionais e sensibilidade à alimentos. Quando validado, este processo servirá como um importante guia para profissionais na área de genética clínica, desenvolvedores e arquitetos de sistemas de informação para produção de laudos de exames genéticos com exemplos de boas práticas de arquitetura de informação, interfaces com usuário para lidar com compartilhamento de informações genéticas entre pacientes e profissionais de saúde.

O artigo está organizado da seguinte forma: na seção 2, está o referencial teórico e trabalhos relacionados; na seção 3, o processo proposto; na 4, resultados parciais; e por último, na seção 5, estão as considerações finais e os trabalhos futuros.

\section{Referencial Teórico}

A literatura em Interação Humano-Computador tem mostrado a importância de trazer o usuário para o processo de design de software a fim de melhorar a usabilidade de produtos. Metodologias como Design Centrado no Usuário inserem o usuário nesse processo e buscam solucionar diversos problemas comuns a processos que não possuem participação do usuário (Nielsen, 1993; Norman, 2006). Um desses problemas ocorre quando se desenvolvem funcionalidades e/ou interfaces de forma distorcida da desejada/requerida pelo usuário, culminando na má ou nenhuma utilização do software.

Em tecnologias de saúde interativa alguns trabalhos em Design Centrado no Usuário obtiveram resultados positivos (Jaspers, 2008; Vito, et al 2009). Mais especificamente em genética, alguns estudos já consideram a usabilidade em laudos clínicos com dados complexos (Neri, 2012). Algumas empresas já tem produzido laudos híbridos (web e impresso) de excelente arquitetura de informação e usabilidade, como: Pathway, Counsyl, Athletigen e Invitae.

\section{Processo}

O processo criado com base no Design Centrado no Usuário, foi utilizado na geração de laudos em PDF e está sendo utilizado para o laudo web. Atualmente, o laudo em documento digital portável já está sendo liberado a pacientes e o laudo web está em construção. As etapas metodológicas propostas para ambos está descrita a seguir.

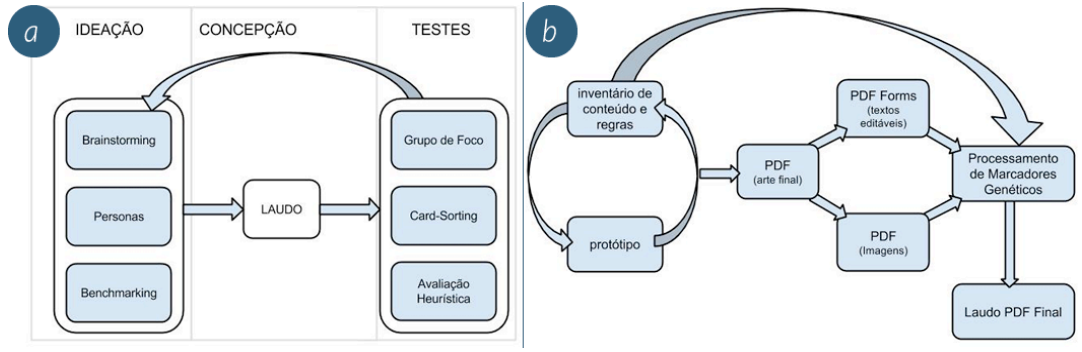

Figura 1. a) Processo de Design Centrado no Usuário para laudos clínicos. b) Processo de concepção de laudo clínico em PDF.

Inicialmente foi feito um levantamento de requisitos através de benchmarking e reuniões de brainstorming com especialistas em negócios, tecnologia, genética e design/experiência do usuário, a fim de definir o público-alvo e entender o contexto. A partir dessas reuniões foram criadas personas, para quem o produto foi pensado ao longo de todo o processo (Figura 1a). 
Através de consultas a especialistas em genética e nutrição foram criadas as interpretações e recomendações associadas a cada variante genética em um inventário de conteúdo e regras. Foram criados simultaneamente alguns protótipos do laudo. Após algumas iterações, um modelo de layout com recomendações por categorias como: sugestões de dieta, exercícios, necessidades nutricionais e sensibilidade aos alimentos entre outros. Além de recomendações o laudo contempla interpretações para cada variante de acordo com o genótipo possuído pelo paciente.

A etapa de concepção de um laudo em PDF é detalhada na Figura 1b. Após vários ciclos de iteração foi validado o laudo com arte final com avaliação heurística. Tendo em posse o artefato, o próximo passo foi o desenvolvimento de um módulo de processamento de marcadores genéticos.

O módulo de processamento de marcadores genéticos é responsável por preencher dinamicamente o formulário PDF, com regras de decisão automatizadas que inserem textos e imagens do inventário de conteúdos de acordo com os genótipos do paciente. Este componente foi desenvolvido com a linguagem de programação Python e bibliotecas open-source de escrita e plotagem de conteúdo em arquivos, além de utilizar técnicas de estatística para mensurar as combinações possíveis de genótipos dos pacientes e identificar perfis de biotipo genético.

Após esta automação, foram realizados testes com usuários. Os participantes dos testes não estavam envolvidos no desenvolvimento das tarefas e nem as viram antes de fazer os testes. Após os testes, os participantes propuseram informações relevantes sobre o conteúdo que puderam nos auxiliar na arquitetura de informação do laudo.

\section{Resultados Parciais}

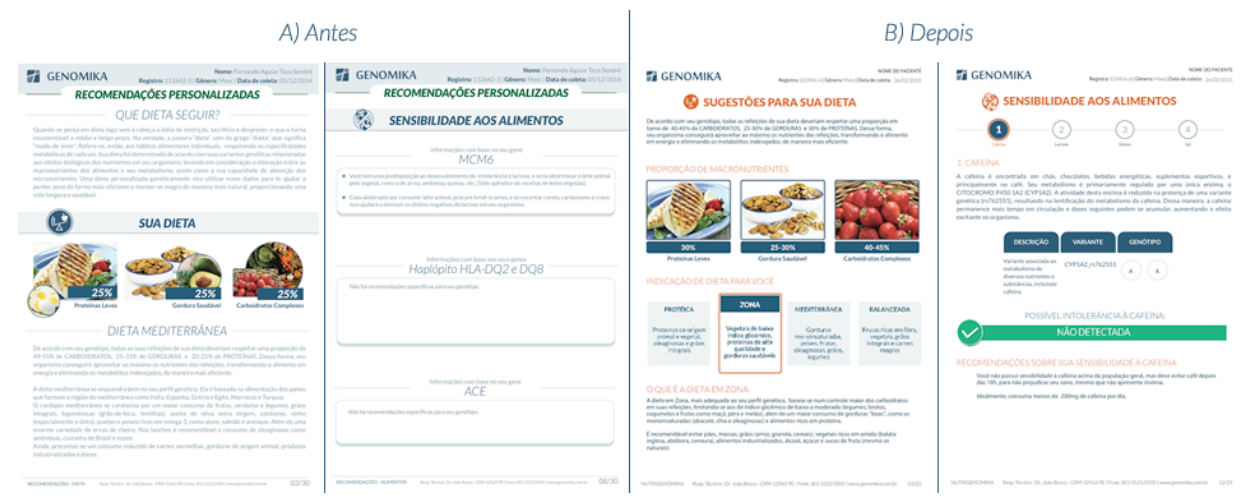

Figura 2. A) Páginas do laudo antes da aplicação das técnicas. B) Páginas após a aplicação das técnicas.

Os primeiros 34 pacientes receberam uma versão PDF do laudo sem nenhuma análise de especialista. Percebemos que não se tinha padrão de cores e formas bem estabelecidos. As cores não tinham o padrão da marca e as formas possuíam uma estética complexa. Além da arquitetura de informações, não ter um padrão. Um processo de simplificação foi feito. Iniciando pela reformulação do inventário de conteúdo e seguido por avaliação heurística, de onde obtivemos contribuição.

Além das melhorias estéticas, a arquitetura de informações também foi melhorada. Aplicamos alguns princípios do design de interação no laudo PDF. O paciente agora pode saber o quanto percorreu no laudo e o quanto falta a percorrer, 
podendo ir direto a informação que lhe interessa mais facilmente. Ilustramos na Figura 2 duas das páginas do laudo antes e após aplicação das técnicas do processo proposto.

Após melhorias, o laudo foi liberado para mais 8 pacientes. Executamos testes por cardsorting, a fim de checar se as categorias e textos estão fáceis de serem entendidos e o grupo de foco com usuários para checar o laudo completo. $\mathrm{O}$ cardsorting trouxe contribuições quanto a legibilidade.

\section{Considerações Finais}

Devido à alta complexidade de informações em laudos de testes genéticos, se faz necessário a criação de produtos que privilegiasse o estudo da arquitetura de informações e usabilidade. Este artigo demonstrou o processo de construção de um laudo genético com informações nutricionais, discutindo a importância da participação de usuário em projetos de tecnologias interativas para saúde. Mais detalhes sobre o processo precisarão ser detalhadas e avaliadas para trabalho futuro.

A próxima etapa será aplicar o mesmo processo para a interface web do laudo, e simultaneamente validar o ciclo de desenvolvimento do laudo para impressão. Como trabalhos futuros se propõe também a possibilidade dos especialistas de saúde se envolverem mais no processo. Os especialistas poderão realizar alterações diretas no modelo de informações em uma interface administrativa para validação e testes de laudos gerados. Além disso, questionários de usabilidade e satisfação serão aplicados à usuários. Espera-se como resultado a agilização e redução de risco de erros, visto que se elimina etapas manuais do processo; além de melhoria da compreensão das informações; velocidade em encontrar as informações; e o impacto disso no tratamento realizado pelos pacientes e na avaliação dos profissionais de saúde sobre quais tipos de informações foram melhor apresentadas para o perfil dos pacientes alvo.

\section{Referências}

Cariaso, M., \& Lennon, G. (2012). SNPedia: a wiki supporting personal genome annotation, interpretation and analysis. Nucleic acids research, 40, D1308-D1312.

Hamosh, A., Scott, A. F., Amberger, J. S., Bocchini, C. A., \& McKusick, V. A. (2005). Online Mendelian Inheritance in Man (OMIM), a knowledgebase of human genes and genetic disorders. Nucleic acids research, 33(suppl 1), D514-D517.

De Vito Dabbs, A., Myers, B. A., Mc Curry, K. R., Dunbar-Jacob, J., Hawkins, R. P., Begey, A., \& Dew, M. A. (2009). User-Centered Design and Interactive Health Technologies for Patients. Computers, Informatics, Nursing : CIN, 27(3), 175.

Jaspers, M. W. M. (2008). A comparison of usability methods for testing interactive health technologies: Methodological aspects and empirical evidence. International Journal of Medical Informatics, Volume 78 , Issue 5 , 340 - 353.

Neri, P. M. et al. (2012). Usability of a novel clinician interface for genetic results. Journal of Biomedical Informatics , Volume 45 , Issue 5 , 950 - 957

Nielsen, Jakob. (1993). Usability Engineering. Morgan Kaufmann.

Norman, Donald A. (2006). O Design do dia-a-dia. Rio de Janeiro: Ed. ROCCO. 